\section{Irrigation Scheduling Programs for Cabbage and Zucchini Squash}

\author{
James E. Ells ${ }^{1}$, Ann E. McSay', \\ and E.G. Kruse ${ }^{2}$
}

Additional index words. Brassica oleracea var. capitata L., Cucurbita pepo var. Melopepo L., water-use efficiency, crop coefficients

Summary. Irrigation scheduling programs were developed for cabbage and zucchini squash that produced high yield and water-use efficiency with a minimum number of irrigations. The irrigation programs are based on a soil water balance model developed by the USDA. The procedure involved selecting irrigation programs developed for similar crops and using them as standards for cabbage and zucchini for three growing seasons. The treatments involved irrigation levels higher and lower than the standard. After the third year, the best treatment for each year was selected. Coefficients for the standard model then were adjusted by trial and error to produce a program that called for the same number of irrigations and the same amount of water as the best-performing treatment when using the same weather data. These revised programs for cabbage and zucchini squash are available on computer disks and may be used on any IBM compatible PC provided wind, temperature, solar radiation, humidity, and precipitation data are available,

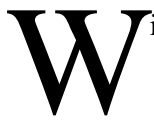

ith the increasing population and industrialization of Colorado, there is a greater demand upon its finite water resources. This affects all water users, including

'Department of Horticulture, Colorado State University, Fort Collins, CO 80523.

${ }^{2}$ USDA/ARS Agricultwral Engineering Research Center, Colorado State University, Fort Collins, CO 80523.

Funding provided by Colorado Agricultural Experiment Station (Project 756), Colorado State Unip. Development Fund (Project 5195), and Colorado State Univ. Cooperative Extension (Project 6101). vegetable growers. Because it is nearly impossible to produce vegetables in Colorado without irrigation, an effort is being made to determine the water needs of major vegetable crops.

The water requirements of a crop are determined by meteorological conditions and stage of development. Because meteorological conditions (temperature, wind, humidity, and solar radiation) influence evapotranspiration (Et), one should be able to estimate Et when the meteorological conditions are known. This requires measuring the meteorological factors and developing appropriate relationships to translate these measurements into water loss through Et. Penman (1948) developed physically based relationships between climatic conditions and evaporation. Since then, these relationships have been modified and incorporated into a practical computerized irrigation scheduling programs by others (Jensen 1969; Kincaid and Heermann, 1974).

The primary advantage of the computerized scheduling program (SCHED) over soil-water measuring devices, such as tensiometers and gypsum blocks, or devices to measure the evaporative power of the air, such as evaporative pans and Bellani plates (Carder, 1968), is that irrigation times and amounts can be predicted several days in advance. Also, soil-water measuring devices have to be situated to represent the moisture condition of the entire field, whereas SCHED output is valid for any field represented by a station supplying weather data. SCHED, given appropriate weather data and characteristics of the soil and crop, will indicate when a given field should receive water and how much should be applied. After the program has been verified for a given crop and field, its use may allow less-frequent field visits for monitoring soil water conditions.

SCHED calculates daily water deficit using: 1) water-holding capacity of the soil, 2) current assumed rooting depth, 3) amount of effective rain (i.e., rain that contributes to the water supply in the predetermined root zone; deep percolation is not counted as rain), and 4) the calculated Et. When soil water is depleted to a predetermined percentage, the program calls for an irrigation and specifies the amount of water to apply to recharge soil moisture to field capacity. SCHED 
predicts irrigation dates up to 10 days in advance, assuming average weather conditions. The actual amount of rain that falls on each field should be entered into the program prior to each update. Rainfall should be measured within a few hundred yards of the field being scheduled. Similarly, the amount and date of irrigation water applied to each field must be input before updating.

This study used a computer irrigation program (SCHED) developed by the USDA/ARS (Jensen, 1969) for predicting irrigation frequency and amounts for field crops. SCHED was modified for personal computers with DOS operating systems. Kruse et al. (1987) and Ells et al. (1989) supplied crop coefficients for use with onions and cucumbers, both major vegetable crops in Colorado.

The irrigation scheduling approach was to maintain a daily soil water budget using SCHED. Daily crop water use or Et was calculated by multiplying the reference Et by crop coefficients based on crop and stage of growth (Kincaid and Heermann, 1974). The equation used was:

$\mathrm{Et}=\mathrm{Kc} \operatorname{Etr}+\mathrm{Kr}(0.9-\mathrm{Kc}) \operatorname{Etr}[1]$

where Et = daily evapotranspiration; Etr = potential evapotranspiration for reference crop (alfalfa); Kc = crop coefficient determined by the stage of growth and soil water depletion; and $\mathrm{Kr}=$ coefficient taking on the values of 0.8 for the first day, 0.5 for the second day, 0.3 for the third day, and 0.0 for subsequent days following rainfall or an irrigation that wets soil surface.

$$
\mathrm{Kc}=\mathrm{K}_{\mathrm{co}} \mathrm{Ks}
$$

where $\mathrm{K}_{\mathrm{co}}=$ ratio of Et for crop in question to the reference crop Et, when soil water is not limiting and soil surface evaporation is negligible; and $\mathrm{Ks}=$ stress factor that drops below 1.0 as soil water is depleted and becomes less available to the crop (Kincaid and Heermann, 1974).

SCHED has a feature that allows the estimated root zone depth to increase during the season. This was used for one treatment the first year, but was abandoned when results did not meet expectations.

Initial coefficients for zucchini were obtained from previous work on cucumbers (Ells et al, 1989) and coef- ficients for cabbage were adapted from unpublished irrigation studies conducted by the U.S. Bureau of Reclamation, Irrigation Management Services, Denver, Colo. Both cabbage and zucchini were grown for three successive seasons using an irrigation treatment that supplied the estimated soil water depletion at each irrigation. Additional treatments supplied either more or less water during the season, with yields determining which level of irrigation was most appropriate. If there were no differences in yield among treatments, then differences among water use efficiencies were examined. When yield differences did not materialize, water-use efficiency differences did; therefore, the most water-efficient treatment became the preferred treatment for that experiment.

Treatments used the 2nd and 3rd years were modified according to their performance of the previous year (see treatment descriptions, Table 1). After the 3rd year, the treatment that offered the best combination of high yield, low number of irrigations, and high water-use efficiency was selected as the preferred treatment.

After 3 years of field research, the overall preferred treatmentwas selected and each year of the study was resimulated using SCHED, but varying the
$\mathrm{K}_{\mathrm{co}}$ values, rooting depth assumptions, and allowed depletions until the SCHED output closely duplicated the frequency and irrigation depths applied to the preferred treatment. These coefficients then were substituted for the coefficients that were used originally in SCHED and are the coefficients reported here.

Field studies were conducted at the Colorado State Univ. Horticulture Field Research Center in Fort Collins on Nunn clay loam (Aridic Arguistoll) with $2.7 \%$ organic matter and a water-holding capacity of $9.9 \mathrm{~cm}$ of water/m between $33.8 \mathrm{kPa}$ and 1.5 $\mathrm{MPa}$. A randomized complete-block design with four replications was used for all experiments.

'Rio Verde' cabbage (NorthrupKing \& Co., Gilroy, Calif.), and 'Ambassador' zucchini (Petoseed Co., Inc., Saticoy, Calif.) seed were planted in soil that had been fertilized according to soil test recommendations, and seedling stands were produced by sprinkling with a portable irrigation system. The final sprinkler irrigation occurred after stand establishment to bring the root-zone soil to field capacity. At this point, irrigation scheduling was initiated, and all subsequent water received by the plots either by irrigation or by rain was recorded through harvest.

Table 1 . Water received by cabbage and zucchini squash during the irrigation study periods, 1987-1989.

\begin{tabular}{|c|c|c|c|c|c|}
\hline \multirow[b]{3}{*}{ Treatment } & \multirow{3}{*}{$\begin{array}{c}\text { Depletion } \\
\text { applied (\%) }\end{array}$} & \multicolumn{4}{|c|}{ Irrigations and amounts ${ }^{z}$} \\
\hline & & \multicolumn{2}{|c|}{ Cabbage } & \multicolumn{2}{|c|}{ Zucchini } \\
\hline & & No. & Inches & No. & Inches \\
\hline \multicolumn{6}{|c|}{1987} \\
\hline $\mathrm{T}_{1}$ & 130 & 13 & 25.0 & 11 & 21.2 \\
\hline $\mathrm{T}_{2}^{2}$ & 100 & 13 & 21.0 & 11 & 17.6 \\
\hline $\mathrm{T}_{3}$ & 70 & 13 & 16.6 & 11 & 13.4 \\
\hline $\mathrm{T}_{4}^{\mathrm{y}}$ & 100 & 16 & 22.3 & 13 & 18.4 \\
\hline Rain included & & & 4.5 & & 3.9 \\
\hline \multicolumn{6}{|c|}{1988} \\
\hline $\mathrm{T}_{1}$ & 100 & 12 & 19.7 & 10 & 16.9 \\
\hline $\mathrm{T}_{2}$ & 80 & 12 & 16.4 & 10 & 14.3 \\
\hline $\mathrm{T}_{3}$ & 60 & 12 & 13.2 & 10 & 11.6 \\
\hline $\mathrm{T}_{4}$ & 40 & 12 & 10.0 & 10 & 8.9 \\
\hline Rain included & & & 3.6 & & 3.6 \\
\hline \multicolumn{6}{|c|}{1989} \\
\hline $\mathrm{T}_{1}$ & 120 & 10 & 24.6 & 10 & 24.1 \\
\hline $\mathrm{T}_{2}$ & 100 & 10 & 21.4 & 10 & 20.3 \\
\hline $\mathrm{T}_{3}$ & 80 & 10 & 18.2 & 10 & 17.2 \\
\hline $\mathrm{T}_{4}^{\circ}$ & 60 & 10 & 15.0 & 10 & 14.3 \\
\hline Rain included & & & 5.4 & & 5.4 \\
\hline
\end{tabular}


After SCHED was put into effect, the portable irrigation system was removed, the plots (cabbage: $24 \times 9 \mathrm{ft}$; zucchini: $24 \times 18 \mathrm{ft}$ ) were marked out, and the plots were furrowed in preparation for furrow irrigation. The plots consisted of two harvest rows and a buffer row to separate adjoining plots. There were three furrows associated with each cabbage plot, which had 3 -ft row spacing, and six furrows associated with each zucchini plot, which had 6-ft row spacing. The furrows were blocked at the ends of the plots and acted as level furrows, retaining all irrigation and rainfall until it infiltrated.

SCHED was programmed to call for an irrigation when $50 \%$ of the available water was depleted from the root zone. One treatment in each test received the water required to regain field capacity. Other treatments were irrigated on the same day, but received more or less water. This resulted in an equal number ofirrigations for all treatments. Scheduling light, frequent irrigations by assuming a shallow root zone proved inefficient because the nearly continuously wet soil surface caused more evaporation that was accounted for by SCHED.

Domestic water $(80 \mathrm{ppm}$ total dissolved solids) was used to irrigate the blocked furrows. Irrigation volumes were metered and applied through a manifold, which distributed water evenly to three furrows. When applying the amount of water called for by the program to the furrows, $100 \%$ irrigation efficiency was assumed. The program, however, automatically deducts for water lost from a wet soil surface.

Harvesting occurred as the fruit reached marketable size. Zucchini harvest of subplots $(20 \times 12 \mathrm{ft})$ within the irrigated plots began in July and continued, semi-weekly, into September. The fruits were graded, counted, and weighed according to size. Similarly, cabbage was selectively harvested two to four times a season from subplots $(20 \times 6 \mathrm{ft})$ within the irrigated plots by cutting, then counting and weighing the mature heads from each plot.

The rain and irrigation water received by the treatments during irrigation scheduling are shown in Table 1 . The water depths presented were used to calculate water-use efficiency for each treatment.

\section{Cabbage}

In all 3 years there was a tendency for yields to increase with the amount of water applied; however, only in

1988 was the correlation between water and yield significant (Fig. 1).

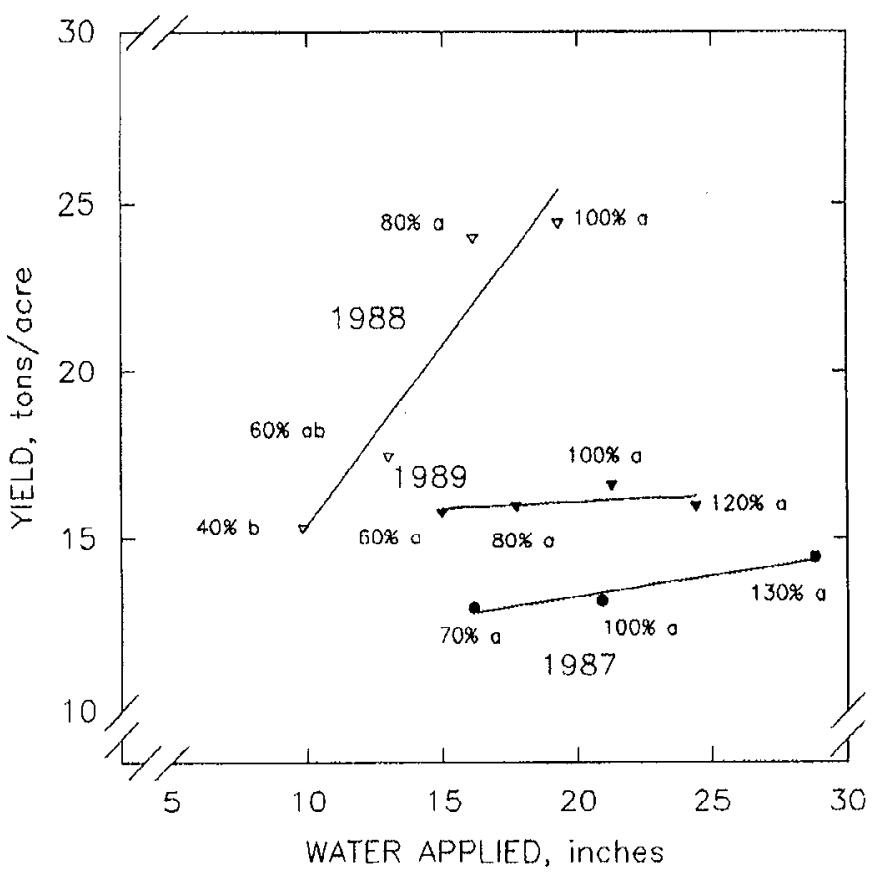

Fig. 1. Cabbage yield (tons/acre) as affected by total water applied (inches). Points are treatments that are labeled with percent of depletion applied at each irrigation. Treatments on a given line followed by different letters are different at $\mathrm{P}=0.05$. Regression equations and $\mathrm{r}$ palues are as follows:

$\begin{array}{ll}\text { 1987: } y=10.29+0.158 x & \mathrm{r}=0.06^{\mathrm{NS}} \\ 1988: y=4.62+1.075 x & \mathrm{r}=0.66^{*} \\ 1989: y=15.33+0.039 x & \mathrm{r}=0.06^{\mathrm{NS}}\end{array}$

Ns, Not significant or significant at $\mathrm{P}=0.05$ to 0.01 .

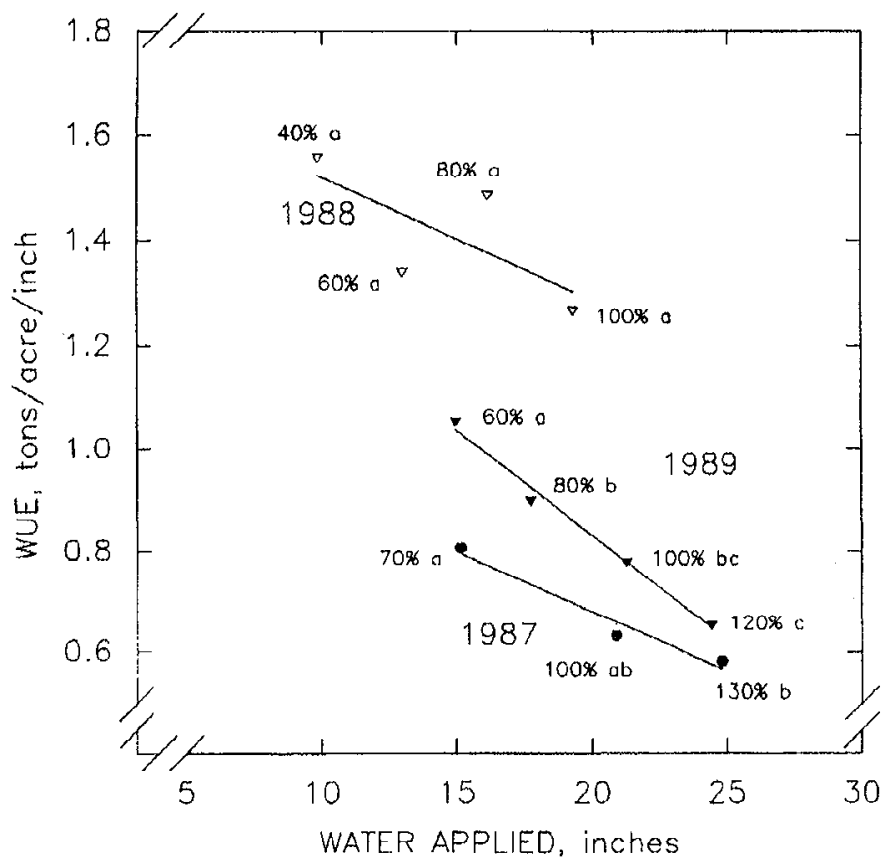

Fig. 2. Cabbage water use efficiency (tons/acre per inch) as affected by total water applied. Points are treatments that are labeled with percent of depletion applied at each irrigation. Treatments on a given line followed by different letter are different at $\mathrm{P}=0.05$. Regression equations and $\mathrm{r}$ values are as follows:

$\begin{array}{ll}\text { 1987: } y=1.22-0.026 x & \mathrm{r}=0.62^{*} \\ \text { 1988: } y=1.75-0.023 x & \mathrm{r}=0.26^{N S} \\ 1989: y=1.65-0.041 x & \mathrm{r}=0.80^{* *}\end{array}$

ws, ${ }^{* * *}$ Not significant or significant at $\mathrm{P}=0.05$ to 0.01 or 0.01 , respectively. 
Water-use efficiency declined with increased applications of water in all 3 years. There was a significant correlation in 1987 and 1989 between water applied and cabbage produced per inch of water, with less water giving greater water-use efficiency (Fig. 2).

The preferred treatment for 1987 was the $70 \%$ water deficit replacement treatment because it produced yields similar to the $100 \%$ treatment with only $70 \%$ of the water (Fig. 1). In addition, it had the highest water-use efficiency, although not significantly higher than the $100 \%$ treatment (Fig. 2).

In 1988, there were no significant yield differences among $60 \%, 80 \%$, and $100 \%$ depletion treatments (Fig. 1). Because there were no differences in water-use efficiency (Fig. 2), and all treatments received 12 irrigations, the $80 \%$ treatment is preferred because it used less water than the $100 \%$ treatment.

The 1989 study produced no yield differences for applications between

Table 2. Revised crop coefficient equations for USDA irrigation scheduling procedure (SCHED) for cabbage and zucchini squash, 1987-1989.

\begin{tabular}{c} 
Crop coefficient values ${ }^{2}$ \\
Before effective cover After effective cover \\
\hline
\end{tabular}

$\begin{array}{lc} & \text { Cabbage } \\ \mathrm{A}=-1.064 & \mathrm{~A}=-6.864 \times 10^{-7} \\ \mathrm{~B}=1.564 & \mathrm{~B}=5.498 \times 10^{-5} \\ \mathrm{C}=-0.07288 & \mathrm{C}=-7.717 \times 10^{-4} \\ \mathrm{D}=0.08591 & \mathrm{D}=0.5079 \\ \mathrm{~K}_{\mathrm{co}} \text { ranges: } 0.15 \text { minimum, } 0.60 \text { maximum. }\end{array}$

Depth of root zone assumed to be $2 \mathrm{ft}$ from planting to harvest.

Irrigation applied when $37.5 \%$ of available water in root zone had been depleted.
Zucchini
$\mathrm{A}=-1.236 \quad \mathrm{~A}=1.063 \times 10^{-8}$
$\mathrm{B}=2.243 \quad \mathrm{~B}=\mathbf{- 3 . 3 1 0 \times 1 0 ^ { - 5 }}$
$\mathrm{C}=-0.6354 \quad \mathrm{C}=4.746 \times 10^{-4}$
$\mathrm{D}=\mathbf{0 . 2 0 5 2} \mathrm{D}=0.5692$
$\mathrm{K}_{\mathrm{co}}$ ranges: 0.15 minimum, 0.60 maximum.
Depth of root zone assumed to be $2 \mathrm{ft}$ from planting to harvest.
Irrigation applied when $40 \%$ of available water in root zone had been depleted.
${ }^{{ }^{z} \text { Crop coefficients are computed from } K_{c a}=A r^{3}}$ $+B r^{2}+C r+D$, where $K_{c o}$ is the crop coefficient used in SCHED. Before effective cover, $r$ is the fraction of time from planting to effective cover. After effective cover, $r$ is measured in days (Figs. 5 and 6 ). $K_{\text {co }}$ values are valid for cabbage planting dates from $19 \mathrm{Apr}$. to $10 \mathrm{May}$ to 18 May. Effective cover was assumed to have occurred on 25 July for both crops.

$60 \%$ and $120 \%$ of the estimated depletions (Fig. 1). However, the $60 \%$ treat-

ment had the highest water-use efficiency (Fig. 2) and, therefore, became

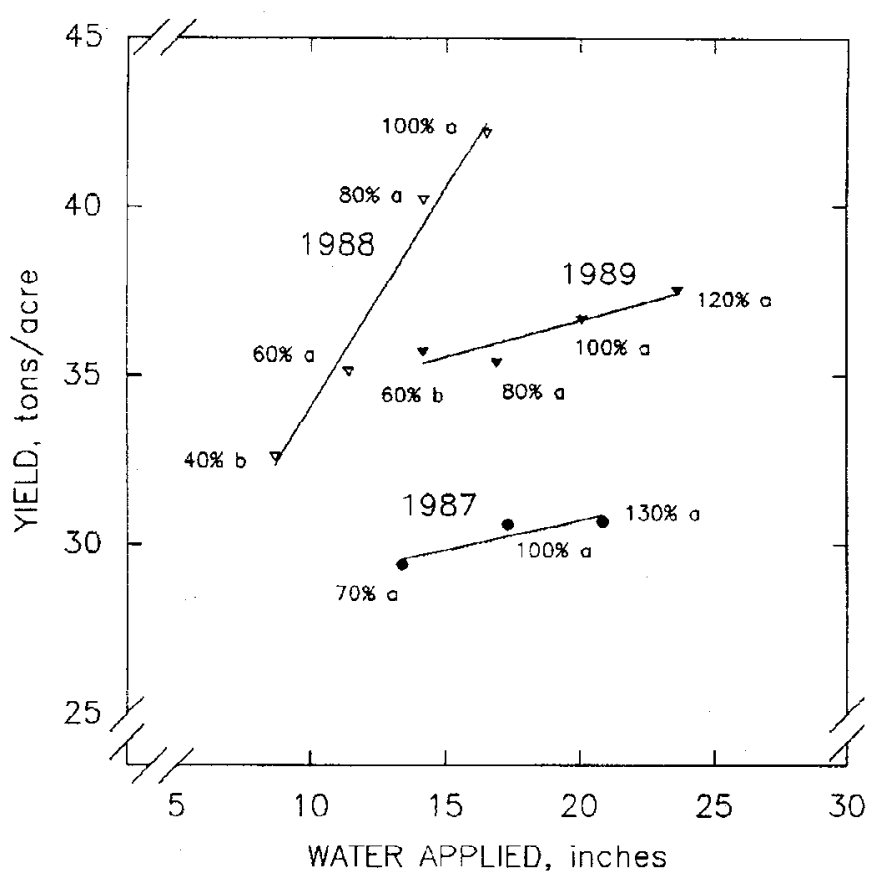

Fig. 3. Zucchini yield (tons/acre) as influenced by total water applied (inches). Points are treatments that are labeled with percent of depletion applied at each irrigation. Treatments on a given line followed by different letter ave different at $\mathrm{P}=0.05$. Regression equations and $\mathrm{r}$ values are as follows:

$\begin{array}{ll}\text { 1987: } y=27.2+0.175 x & \mathrm{r}=0.33^{\text {NS }} \\ \text { 1988: } y=21.1+1.29 x & \mathrm{r}=0.73^{* *} \\ 1989: y=32.2+0.221 x & \mathrm{r}=0.11^{\text {NS }}\end{array}$

${ }^{N s, * *}$ Not significant or significant at $\mathrm{P} \leq 0.01$, respectipely.

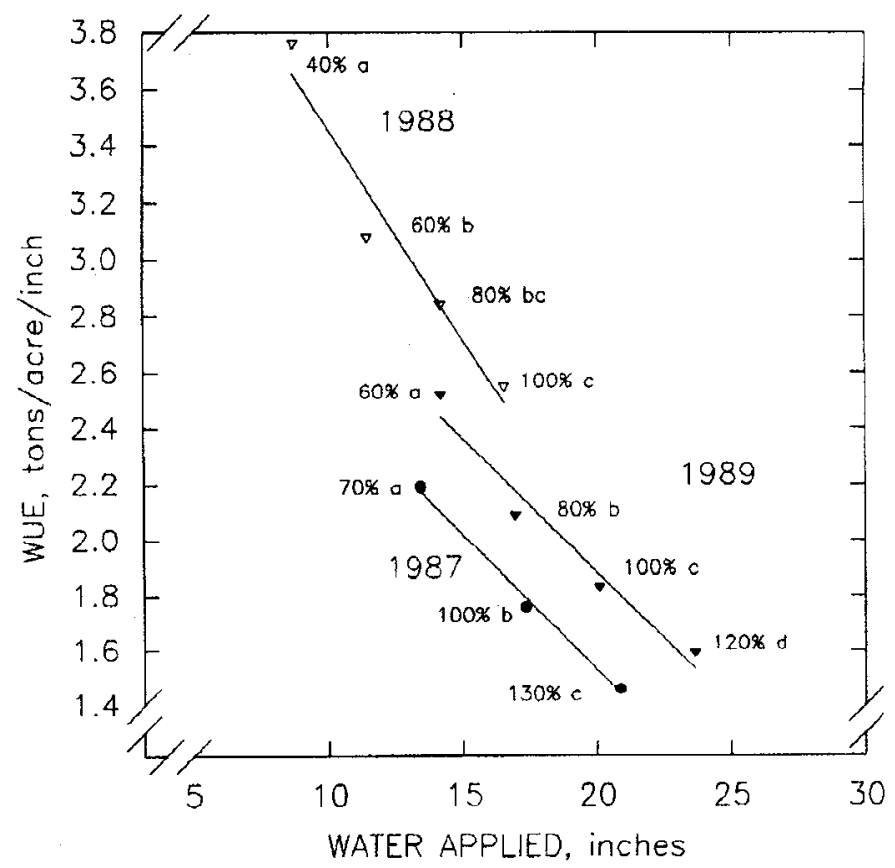

Fig. 4. Zucchini water use efficiency (tons/acre per inch) as affected by total water applied. Points ave treatments that are labeled with percent of depletion applied at each irrigation. Treatments on a given line followed by different letter are different at $\mathrm{P}=0.05$. Regression equations and $\mathrm{r}$ values are as follows:

$\begin{array}{ll}\text { 1987: } y=3.48-0.097 x & \mathrm{r}=0.96^{* *} \\ \text { 1988: } y=4.92-0.147 x & \mathrm{r}=0.82^{* *} \\ \text { 1989: } y=3.80-0.096 x & \mathrm{r}=0.66^{* *}\end{array}$

** $\mathrm{p}<n$ กI 


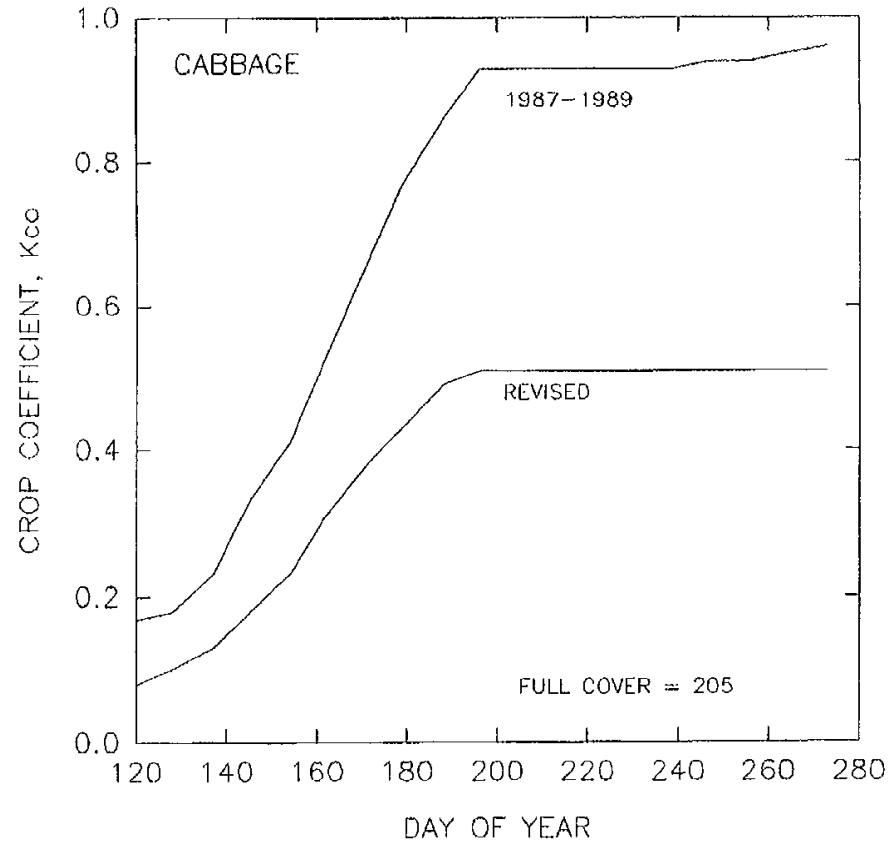

Fig. 5. Crop coefficient curves for irrigation scheduling of cabbage. The 1987-89 line represents the coefficients assumed during the 3-year field study. The revised line simulates the irrigation treatwent that gave the bighest yiold and best water-use efficiency in cach of 3 years.

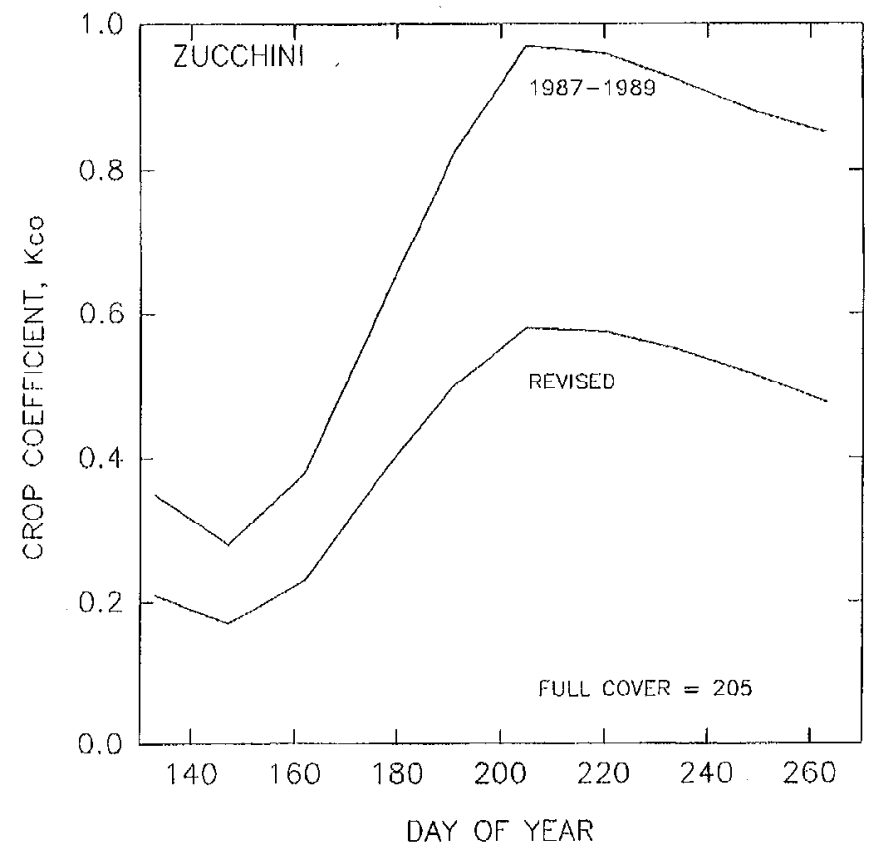

Fig. 6. Crop coefficient curves for irrigation scheduling of zucchini. The 1987-89 line represents the coefficients assumed during the 3-year field study. The revised line simulates the irrigation treatment that gave the highest yield and best water-use efficiency in each of 3 years.

the preferred treatment.

In conclusion, the preferred treatments called for irrigation depths equal to $70 \%, 80 \%$, and $60 \%$ for 1987,1988 , and 1989 , respectively. The revised crop coefficients listed in Table 2, when used with SCHED, would schedule irrigations equivalent to $70 \%$ of those assumed at the beginning of this study. While the 24-inch root depth used in this model may seem deep for a devel- oping crop, it gave better water-use efficiency because it required fewer irrigations and less water, and the yields were just as high.

\section{Zucchini}

The number and total depth of irrigations, along with precipitation, is given for zucchini in Table 1. Depths include all water received by the squash from the time irrigation scheduling began until the final harvest for each year. The values in the last column were used to compute water use efficiencies.

There was a tendency for yields to increase with water applied, with positive correlations in all 3 years (Fig. 3). However, only in 1988 was the regression significant. In 1987 , all treatments yielded the same. Therefore, there appears to be no reason to apply more than $70 \%$ of the depletion. In 1988 , the $80 \%$ and $100 \%$ treatments produced the same and, therefore, $80 \%$ of depletion seems appropriate. All treatments produced the same in 1989 and, therefore, the least amount of water applied, $60 \%$, appears adequate.

Correlations of water-use efficiency and depth of water applied were significant for all years, with greater application of water resulting in lessefficient water use (Fig. 4). The 70\% depletion treatment produced greatest water-use efficiency in 1987, the $40 \%$ treatment was best in 1988 , and the $60 \%$ treatment was best in 1989 .

With preferred treatments of $60 \%$, $80 \%$, and $60 \%$ for 1987,1988 , and 1989 , respectively, the program was modified to recommend $67 \%$ of the water it had specified originally.

\section{Crop coefficient revision}

During the 3 years of this study, SCHED overestimated water used by both cabbage and zucchini. Therefore, the crop coefficients were revised by trial and error until resimulation with the 1989 weather data predicted irrigation regimes approaching $70 \%$ and $67 \%$, respectively, of the water applied to cabbage and zucchini by the $100 \%$ of depletion treatments. Equations for computing these revised coefficients are given in Table 2, and the revised curves are presented in Figs. 5 and 6.

A comparison of actual and revised number of irrigations and water applied to cabbage and zucchini are found in Table 3. The revised, simulated treatments are shown to compare favorably with the best experimental treatments of each year. Using this as a basis, the SCHED programs have been revised to maximize both yields and water-use efficiency of cabbage and zucchini. These SCHED programs are now available from us for use on IBM-compatible microcomputers, to those who may have use for them. See Resources Available on p. 
Table 3. Comparison of actual and revised number of irrigations and water applied to cabbage and zucchini for the best irrigation treatment, 1987-1989.

\begin{tabular}{|c|c|c|c|c|c|c|c|}
\hline \multirow[b]{2}{*}{ Variable } & \multicolumn{7}{|c|}{ Year } \\
\hline & \multicolumn{2}{|c|}{1987} & \multicolumn{3}{|c|}{1988} & \multicolumn{2}{|c|}{1989} \\
\hline \multicolumn{8}{|c|}{ Cabbage } \\
\hline Treatment & $\mathrm{T}_{3}$ & $\mathrm{RS}^{\mathrm{z}}$ & $\mathrm{T}_{2}$ & $\mathrm{~T}_{3}$ & RS & $\mathrm{T}_{4}$ & RS \\
\hline No. irrigations & 13 & 12 & 12 & 12 & 12 & 10 & 11 \\
\hline Water applied (inches) & 12.0 & 11.8 & 12.9 & 9.7 & 11.5 & 9.6 & 10.9 \\
\hline \multicolumn{8}{|c|}{ Zucchini } \\
\hline Treatment & $\mathrm{T}_{3}$ & $\mathrm{RS}$ & $\mathrm{T}_{2}$ & & RS & $\mathrm{T}_{4}$ & RS \\
\hline No. irrigations & 11 & 10 & 10 & & 10 & $10^{4}$ & 10 \\
\hline Water applied (inches) & 9.6 & 10.6 & 10.7 & & 10.4 & 9.0 & 10.4 \\
\hline
\end{tabular}

464 of this issue of HortTechnology for details.

\section{Literature Cited}

Carder, A.C. 1968. The black Bellani-type atmometer as an instrument to estimate evapotranspiration of crop plants. Intl. J. Biometeorol. 12(1):11-14

Ells, J.E., E.G. Kruse, and A.E. McSay. 1989. Scheduling irrigations for cucumbers. HortScience 24(3):448-452.

Jensen, M.E. 1969. Scheduling irrigations with computers. J. Soil \&Water Conserv. 24(8): 193-195

Kincaid, D.C. and D.F. Heermann. 1974. Scheduling irrigations using a programmable calculator. USDA/ARS Bul. NC12.

Kruse, G.E., J.E. Ells, and A.E. McSay. 1987. Comparison of two onion irrigation scheduling programs. J. Amer. Soc. Hort. Sci. 112(5):738-742.

Penman, H.L. 1948. Natural evaporation from open water, bare soil and grass. Proc. R. Soc. London, Ser. A 193:120-145. 